\title{
Proceeding
}

Supplementary Issue: Summer Conferences of Sports Science. First International Conference in Iraq on Sport for Peace, 4 April 2019. Baghdad Science Institute, Baghdad, Iraq.

\section{What determine the innovation performance of Sports SMEs in Thailand?}

\author{
CHAYANAN KERDPITAK ${ }^{1} \checkmark$, CHAIRIT THONGRAWD1, NIRUEMOL MANEESAWANGWONG², MONTRE \\ JUNKTANASOMBUT2
}

${ }^{1}$ Suan Sunandha Rajabhat University, Bangkok, Thailand

${ }^{2}$ Ramkhamheang University, Bangkok, Thailand

\begin{abstract}
The study can add to the existing literature on SMEs, service innovation, and dynamic capabilities by the identified mechanism. The way in which service innovation can be improved in SMEs has been explained in this research. The managerial and theoretical guidelines have been offered to achieve the competitive advantages based on service. This has been achieved by showing the way in which ACAP (dynamic knowledge capability) can be encouraged through internal and external collaboration. The study has used the SEM-PLS to analyse the data. The final sample comprises of 100 firms and response rate is 14.5 percent. It has been shown by the findings that both innovation types are derived through the similar mechanisms of knowledge. The positive influence created on product innovation by ACAP has been confirmed by previous research. The performance of service innovation can be influenced positively through use of external knowledge via RACAP. Therefore, the performance of service innovation can be achieved by an SME in manufacturing sector when it possesses the ability to use the relevant knowledge gained from external sources. Moreover, it must have the capability of assimilating and utilizing the acquired knowledge. It has been suggested by this research that employee collaboration should be ensured by SMEs in the process of service innovation. However, future studies can analyse the way in which the adoption of this mind set can be established by the manufacturing SMEs. Keywords: Innovation; Technology; Sports; SMEs; Thailand.
\end{abstract}

\section{Cite this article as:}

Kerdpitak, C., Thongrawd, C., Maneesawangwong, N., \& Junktanasombut, M. (2019). What determine the innovation performance of Sports SMEs in Thailand? Journal of Human Sport and Exercise, 14(5proc), S2172-S2186. doi:https://doi.org/10.14198/jhse.2019.14.Proc5.37

Corresponding author. Graduate School, Suan Sunandha Rajabhat University, Bangkok, Thailand.

E-mail: chayanan.ke@ssru.ac.th

Supplementary Issue: Summer Conferences of Sports Science. First International Conference in Iraq on Sport for Peace, 4 April 2019. Baghdad Science Institute, Baghdad, Iraq.

JOURNAL OF HUMAN SPORT \& EXERCISE ISSN 1988-5202

(c) Faculty of Education. University of Alicante

doi:10.14198/jhse.2019.14.Proc5.37 


\section{INTRODUCTION}

According to the (Kohtamäki \& Partanen ,2016) manufacturing companies have integrated the services in competitive strategy as distinguished feature. The servitization is the shifting of value creation process from trading products to trading solutions. Not only the large size companies like Rolls-Royce Aerospace, Xerox, IBM and General Electric have implement this strategy but the medium and small size enterprises (SMEs) have also implemented (Sutduean, Harakan, \& Jermsittiparsert, 2019).

For instance, or the livestock stalls the small manufacturer of microclimate control system add the IT services to their product to inform about the emergency alerts to the farmers on their mobile phones. For the successful servitization they demand such service innovation (Jermsittiparsert, Sutduean, \& Sriyakul, 2019) by which significant advantage can be established (Valtakoski, Reynoso, \& Maranto, 2019). The capability of achieving the competitive advantage grounded on service innovations which shows its performance. According to Valtakoski et al. (2019), Servitizing companies try for the providing the improved services but for systematically innovative services number of businesses fail. For the achievement of performance of service innovation these failures may occur because there is lack in formal approach of the firm for guiding their service innovation hard work. According to the literature only few studies have explored how SME's may excel the service innovation (Martín-Peña, Sánchez-López, \& Díaz-Garrido, 2019). The important antecedents of performance of service innovation such as innovation culture, delivery systems, efficient operations, and suitable practices for organizational design have been cited by some researchers (Hsiao \& Wu, 2019; Valtakoski et al., 2019). Moreover, it is evident from the literature on open innovation that SMEs are required to adapt to the rapidly changing environment by maintain close association with their stakeholders. In this way, SMEs can improve the process of innovation and delivery suitable products/services (Wu \& Hu, 2018). There is need for insights about the way in which knowledge can be extracted by SMEs from the relationship to improve the performance of service innovation. It is crucial for the manufacturing firms to explore the opportunities for service, which can support in using the external knowledge and there is no need for the R\&D departments to use the internal knowledge (Valtakoski et al., 2019). Different knowledge inputs result in the capabilities for knowledge management for organizational challenges (Wu \& Hu, 2018; Jermsittiparsert \& Srisawat, 2019). In order to improve the capabilities related to knowledge and for gaining performance in service innovation, there is need for developing processes supporting the knowledge sourcing through communication with the internal and external partners (Lee \& Chen, 2019; Rodríguez-Serrano \& Martín-Armario, 2019). The existing internal knowledge should be combined with the external knowledge through inter-firm collaboration before its implementation (Roberts, 2015). In other words, internal collaborative efforts are required for the effective use of external knowledge (Morgan, Anokhin, \& Wincent, 2018; Vrontis, Thrassou, \& Santoro, 2017). The 'non-invented-here' condition may occur in the externally extracted ideas, if there is no collaboration of employees. It is important to have external collaboration for capturing the developing markets and technologies. Therefore, the internal knowledge base of the organization complements it. The sourcing, assimilation and utilization of external knowledge is supported through both the internal and external collaboration. According to the literature studies, the changing capabilities include the coordinated efforts and collective learning by the members of an organization. The literature studies have not explored the social foundations of such capabilities (Fainshmidt \& Frazier, 2017; Wilden, Devinney, \& Dowling, 2016). Considering this, there is need for investigating about the influence internal and external collaboration on ACAF and ultimately the service innovation of SME. The internal collaboration is the level with which the employees are involved in service innovation. On the other side, the external collaboration involves the level of diversity of innovation by external partners. The effects of these variables on the SMEs in sports sector of Thailand have been studied. It has been found that there are positive influences of employee collaboration and search breadth on the PACAP. 
RACAP is derived by employee collaboration that results in improved performance of service innovation. It results in competitive advantages regarding the innovation service. Similarly, it has been affirmed that new mind-sets, strategies, knowledge base, operations, and capabilities are required for service innovation (Benedettini, Neely, \& Swink, 2015). Further, it has been substantiated that a positive influence is created by employee collaboration on the development of ACAP (dynamic capabilities). The literature on dynamic capabilities has been extended by this finding, which was given less focus previously. However, it is still not clear about the influence created on the formation of dynamic capabilities by the organizational members excluding managers (i.e. employees) (Helfat \& Peteraf, 2015). It has been revealed that SMEs depend on the external network diversity for service innovation. The concept of service innovation in the context of SMEs is not researched much by existing studies (Martín-Peña et al., 2019). Novel insights have been given by this article about the dependence of manufacturing SMEs on external networks and their diversity for expansion to the service business because of unavailability of the resources (Kohtamäki \& Partanen, 2016). The existing literature has been reviewed in the next section and hypothesis has been formulated. After defining the measures, sample and method for data analysis, results, and their implications have been presented. Avenues for further research have been suggested.

\section{LITERATURE REVIEW AND HYPOTHESES}

Service innovation performance has been defined as the level to which the competitive advantage is achieved by SME based on the service innovation (Valtakoski et al., 2019). For servitization, the crucial success factor is performance of service innovation (Visnjic, Wiengarten, \& Neely, 2016). The search about the variables influencing the performance of service innovation was started years before. However, there has been increase in research recently (Valtakoski et al., 2019). The antecedents of performance of service innovation have been found as proficient operations, service quality, and delivery systems. These factors have a strong culture for innovation and development of suitable strategy supporting the development of innovative services (Valtakoski et al., 2019). The significance of suitable designs of organizations including the reward structure and collaborative efforts of frontline staff are closely linked with this strategic need (Hsiao \& Wu, 2019; Kowalkowski, Gebauer, \& Oliva, 2017). The literature on dynamic capabilities has been used for predicting the way in which the external and internal capabilities can support the knowledge development, which is crucial for the process of service innovation. The use of external knowledge support firms, which are focused on service, as compared with the internal knowledge creation (Valtakoski et al., 2019). The performance of service innovation is improved through acquisition of knowledge from the external relations such as customers (Meik \& Brock, 2016; Valtakoski et al., 2019). There is need for recognizing the external knowledge before its utilization for achieving the performance in service innovation. A relevant capability is represented by ACAP to improve the performance of service innovation (Valtakoski et al., 2019). It has been noted in the traditional ACAP definition that it is the ability to identify the significance of new information, it assimilation and implementation for the commercial use (Brunswicker \& Vanhaverbeke, 2015). The internal innovation is improved through use of external knowledge, which develops ACAP. It is builds on the prevailing knowledge and information and is path dependent (Brunswicker \& Vanhaverbeke, 2015). ACAP has been used by previous studies as the innovation performance antecedent, considering the benefits for the long-term viability of the firm and innovation of product (Broersma, Van Gils, \& De Grip, 2016). However, three sequential ACAP processes were introduced by Brunswicker and Vanhaverbeke (2015). These processes include identification, assimilation, and exploitation. Broersma et al. (2016) advanced an approach, in which ACAP has been suggested as a dynamic capability, which is referred as the routine and process of organization through which knowledge resources are acquired and used for developing new applications. This has been used in this research (Kogut and Zander, 1992). The ability to renew, expand, and acquire competence with time is implied by the dynamic capabilities. Four complementary dimensions are involved 
in ACAP, which are developed from one another (Broersma et al., 2016). The ability to discover and acquire related external information is referred as acquisition. The knowledge of an organization about the location of potential information sources is defined by acquisition (Asimakopoulos, Revilla, \& Slavova, 2019). The processes and routines of an organization, which allow for determining, processing, and interpreting the acquired information from external sources is referred as assimilation dimension. The ability for modifying and using the external knowledge by combining it with the current knowledge is referred as Transformation. The ability to use the transformed knowledge in the operations of an organization is referred as Exploitation. The process has been divided into two parts by Broersma et al. (2016), which involves PACAP and RACAP. PACAP involves the first two dimensions and the last two dimensions are involved in RACAP. The positive association between performance of product innovation and ACAP has been addressed by the extant literature (Asimakopoulos et al., 2019). A basic assumption is provided by different product and performance of service innovation antecedents that performance of service innovation is the result of ACAP. In order to recognize, gather, and process the external related knowledge, there is need for acquisition and assimilation to improve the innovations of service. However, the competitive advantage can be gained by ACAP only when the knowledge is transformed and utilized (Asimakopoulos et al., 2019). The RACAP of an organization is formed by these two processes (Broersma et al., 2016). For instance, the identification of an emerging market segment or market can be supported through acquiring scientific knowledge from a research institute or a university. Radical innovations can be made from it. The awareness of the managers of SME can be increased by scientific knowledge about the goal developments and new business models. Additional networks based on knowledge can be built through collaborations with the universities (Dada \& Fogg, 2016). The firms are enabled by the resulting knowledge to deal with the needs of customers and respond to the market opportunities in a timely manner (Luño, Saparito, \& Gopalakrishnan, 2016). The information about the needs of customers can help in offering better quality of service. The knowledge about competitors can help in adopting best practices and setting a benchmark. Use of external knowledge can offer competitive advantage for the form including the achievements with service innovation. Internal collaboration is prerequisite for the effective use of external knowledge (Morgan et al., 2018; Vrontis et al., 2017). The success of a firm in service innovation can be achieved by using the external knowledge in combination with the current internal knowledge and using the knowledge, which has been transformed (Roberts, 2015; Valtakoski et al., 2019). There should be positive influence of transforming and using external knowledge (RACAP) on the performance of service innovation.

H1: RABCP has significant impact on the SIP.

H2: PABCP has significant impact on the RABCP.

The significance of social interaction of employees has been stressed by Kleinbaum and Stuart (2014) for the ability of firm to coordinate and comply with the resource based changes. The dynamic capabilities can be developed through willingness, suitable behaviour and ability of employees to cooperate (Wilden et al., 2016). When the social patterns interaction support employees to get involved in the knowledge transformation, this employees' knowledge is translated into ACAP (Hotho, Lyles, \& Easterby-Smith, 2015). These are the processes, which motivate employees for transformation, use, and exchange of information. Similarly, the participation of employees in the process of decision-making has been conceptualized by Roberts (2015) as the determinant of the PACAP of an organization. The capabilities of acquisition and assimilation of a firm are improved by increasing the number of employees in the innovative environment working as receptors (Brunswicker \& Vanhaverbeke, 2015). The external environment is scanned by these receptions and the sourcing of external knowledge is supported (Suda, 2018). In the domain of service innovation, this type of employee collaboration is crucial as the interface for capturing external information is provided by contact personnel. Specifically, the amount of information gathers regarding the issues of customers increased with greater collaboration with the service employees. The internal resources of 
organization are represented by these employees, which can be used by the firm to acquire and asses the information critical for the development of new services (Melton \& Hartline, 2013). Therefore, for acquiring, assimilating, and interpreting the external information, employees can result in new service innovations (Melton \& Hartline, 2013).

The RACAP of an organization is influenced by the collaboration of employees in the process of decision making through increase in the abilities to transform the external information (Roberts, 2015). It has been argued by Brunswicker and Vanhaverbeke (2015) that the city of an organization to develop novel relations is enhanced by the interactions between people having diverse structures of knowledge. Similarly, it is posited by the dynamic capability theory that knowledge can be successfully created by functionally distinct employees including contact employees (Arndt \& Bach, 2015). The ability of an organization for external knowledge transformation is improved by the employee interactions possessing different types of knowledge. It has been previously noted that without the internal knowledge sharing, the effective use of external knowledge cannot be made (Morgan et al., 2018; Vrontis et al., 2017). It was argued by Mennens, Odekerken, and Letterie (2018) that implementation of innovation is supported by collaboration with contact employees as it enables the organization to avail the opportunities for creating new services successfully (Melton \& Hartline, 2013). The ability of the organization to exploit and transform external knowledge is increased through employee collaboration.

H3: EC has significant impact on the PABCP.

From the wider environment, the knowledge comprehension is enhanced through the collaborative competence with the external partners. Access can be granted to the external knowledge through processes of strong alliances as per the theory of dynamic capability. This results in higher performance (Arndt \& Bach, 2015). The significance of external knowledge searchers including suppliers, competitors, and universities has been underscored. The development, sharing, and utilization of knowledge can be enhanced through inter-firm associations. Therefore, it becomes the ACAP's antecedent (Asimakopoulos et al., 2019; Broersma et al., 2016; Brunswicker \& Vanhaverbeke, 2015). The important antecedents of ACAP, which are interorganizational, include the learning from partners and knowledge acquisition from external sources (Lee \& Chen, 2019). Important influence is created through external relations of an organization on the way ACAP evolves, which is a dynamic capability. The knowledge from different external partners is used by the organizations for various purposes (Wu \& Hu, 2018). The propensity of an SME for gaining knowledge from external sources is enhanced through the diversity of innovation between its external partners. The organization accumulates experiential learning when it has diverse relations with the sources of external knowledge. This enables the process of assimilation easier (Asimakopoulos et al., 2019). The organization also becomes able to recognize and gain ideas from the external environment through openness and it increases the available opportunities. The opportunities can be missed when the organization focuses too much internally. In this way, high value is given to the diversity in the portfolio of SME for the external partners (Love \& Roper, 2015). The ability of gaining, utilizing, and assimilating knowledge from different partners is enhanced through search breadth. This is because of experiential learning. Therefore, it is predicted that assimilation capabilities and acquisition are developed through greater level of search breadth.

H4: SBR has significant impact on the PABCB.

H5: SBR has significant impact on the PABCB.

\section{METHODOLOGY}

A large questionnaire was developed to analyse the innovativeness of SMEs in the manufacturing sector. The data was collected from the sports sector of Thailand. When there are less than250 employees in an 
organization, it is referred as an SME. This definition is consistent with the definition of European Union. The formulated questionnaire was sent through email to almost 1711 SMEs. Online survey was conducted, and link was sent to the respondents. In case, there was no response, a reminder email was sent. If this happened again, the letter was sent through post in which printed questionnaire survey was included along with a reply envelop. The survey was answered by almost 246 organizations. The response rate came out as $14.45 \%$, which can be considered sufficient for this research (Broersma et al., 2016; Fernández-Mesa \& Alegre, 2015; Semrau, Ambos, \& Kraus, 2016). The focus of the study was on the way in which performance of service innovation can be achieved by SMEs. It was indicated by 121 SMEs that they are working on at least one innovation in service over the last year. It indicates that $49 \%$ of the SMEs in the target ample had implemented about one innovation in service in the last year. Considering the benefits, which can be achieved through service innovation, very small percentage of SMEs has adopted this. 21 observations were eliminated because of incomplete information or missed values. The final data was based on 100 responses. The data was checked for any potential biasness as it may arise in the SMEs, which have servitized. A two-step process recommended by Harris and Neely (2016) was used in this research for every endogenous variable. The inverse ratio of Mill was not significant for every analysis. The values came out to be p-values: 0.47 , 0.31 , and 0.77 for RACAP, PACAP, and service innovation performance, respectively. The results revealed that there is no issue of selection bias in the result. For determining the non-response bias, t-test was conducted for the difference of responses (early and late) (Gopal \& Thakkar, 2016). There was no significant different between the related variables at 0.05 level of significance.

\section{MEASURES}

\section{Service innovation performance}

The scales proposed have been used for operationalizing the performance of service innovation. For accessing the competitiveness, the scales developed by Kowalkowski et al. (2017) have been used. It was noted by Noor and Aljanabi (2016) and sources Lee and Chen (2019) that there is lack of consensus regard the conceptualization and determination of ACAP specifically for SMEs. The scale developed by Roberts (2015) including three items from the dimension of acquisition has been used by excluding the items, which did not fit with the context of SME in this study.

\section{Employee collaboration}

A scale of three items was used to measure the level with which the contact personnel is involved in the process of service innovation.

\section{Search breadth}

According to Author, search breadth is conceptualized as the number of external partners with whom the organization collaboration in the process of innovation (Hewitt-Dundas \& Roper, 2018).

\section{DATA ANALYSIS}

PLS-SEM approach has been used in this research for hypothesis and model testing. The research becomes able to analyse the manifest and unobserved variables in a simultaneous way. To determine the competitive advantage sources, PLS-SEM method is effective (Hair, Hult, Ringle, \& Sarstedt, 2016). There are several advantages of this technique over others. Initially, it enables the research to deal with the problem of nonnormality in the data (Hair et al., 2016). It was advised by Hair et al. (2016) to adopt Kolmogorov-Smirnov or Shapiro-Wilk tests for the determination of the normality of the data. It is indicated by both the tests that the data is not distributed normally. The test was done for determining kurtosis and skewness and kurtosis by 
working on the general guidelines (Hair, Hult, Ringle, \& Thiele, 2017). The test confirmed that there is nonnormal distribution of data in this study. Moreover, the approach enables the research to work on a relatively small size of sample (Hair et al., 2016). The size of the sample (final 100) was compared to the size of sample used in a similar study by adopting PLS-SEM. For determining the values of R2 at 0.05 level of significance, it was recommended by Hair et al. (2016) to use the minimum size of sample in PLS-SEM. In this research, there are five arrows and 45 observations are required for determining the values of R2 to be 0.25 at 0.05 level of significance. Therefore, the sample used in this study is relatively large. Further, the formative and reflective, both constructs can be handled using PLS-SEM approach (Hair et al., 2016; Sarstedt, Hair, Ringle, Thiele, \& Gudergan, 2016). Moreover, RACAP and PACAP are regarded as formative and reflective constructs. Employee collaboration is the reflective construct. This is similar as the operationalization is regarded as a dynamic capability. Because of these benefits offered by PLS-SEM, this has been used in this research. SmartPLS 3.0 has been applied for research analysis (Ringle, Wende, \& Becker, 2015). Two steps are involved in the model assessment. The measurement or the outer model has been evaluated in the initial phase. In this, the manifest variables are connected to the unobserved variables. A standard algorithm of PLS-SEM has been used and missing values have been deleted according to case.

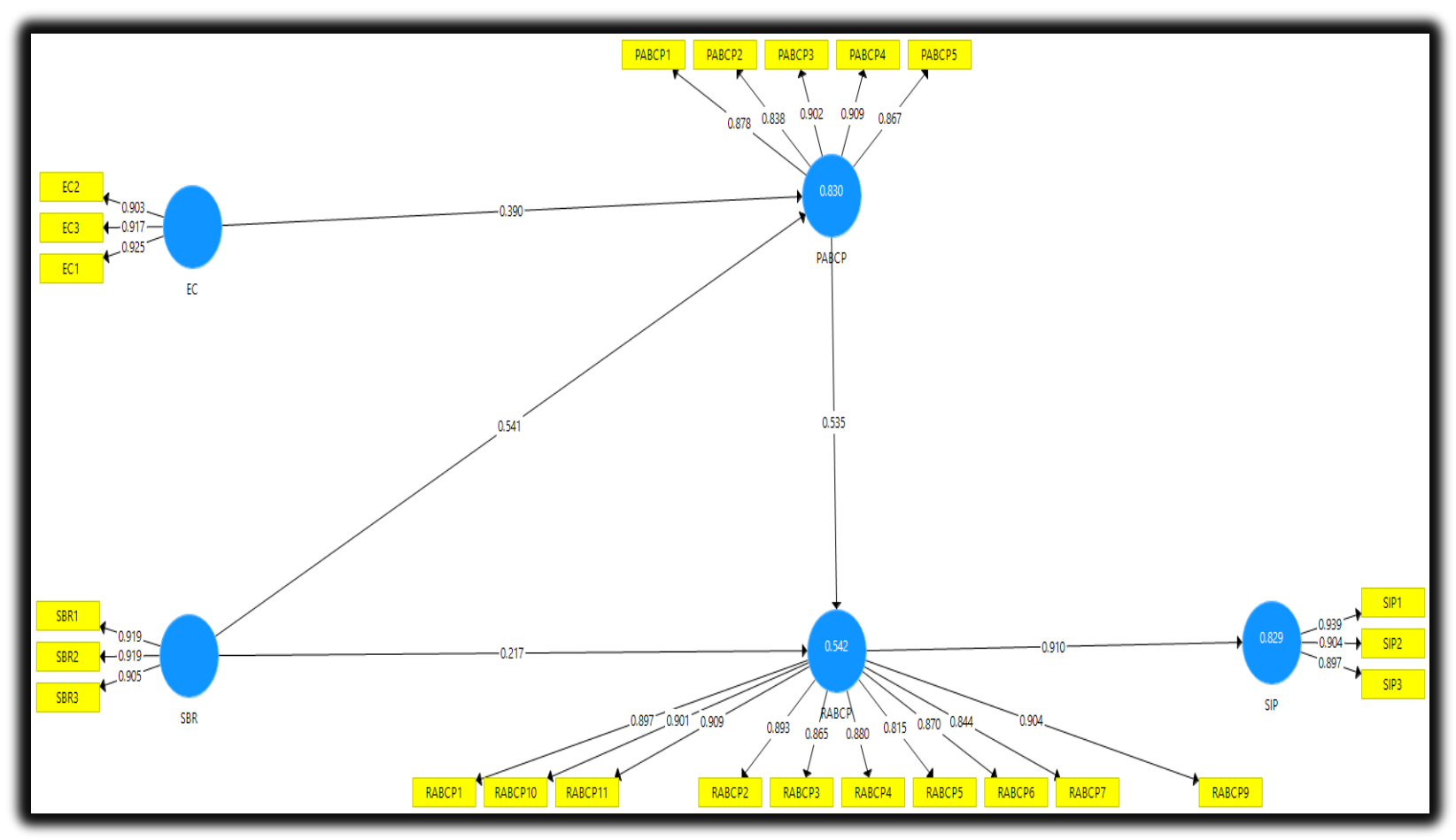

Figure 1. Measurement Model.

Table 1. Outer Loadings.

\begin{tabular}{|l|l|l|l|l|l|}
\hline & EC & PABCP & RABCP & SBR & SIP \\
\hline EC2 & 0.903 & & & & \\
\hline EC3 & 0.917 & & & & \\
\hline PABCP1 & & 0.878 & & & \\
\hline PABCP2 & & 0.838 & & & \\
\hline PABCP3 & & 0.902 & & & \\
\hline PABCP4 & & 0.909 & & & \\
\hline
\end{tabular}




\begin{tabular}{|l|l|l|l|l|l|}
\hline PABCP5 & & 0.867 & & & \\
\hline RABCP1 & & & 0.897 & & \\
\hline RABCP10 & & & 0.901 & & \\
\hline RABCP11 & & & 0.909 & & \\
\hline RABCP2 & & & 0.893 & & \\
\hline RABCP3 & & & 0.865 & & \\
\hline RABCP4 & & & 0.880 & & \\
\hline RABCP5 & & & 0.815 & & \\
\hline RABCP6 & & & 0.870 & & \\
\hline RABCP7 & & & 0.844 & & \\
\hline RABCP9 & & & 0.904 & & \\
\hline SBR1 & & & & 0.919 & \\
\hline SBR2 & & & & 0.919 & \\
\hline SBR3 & & & & 0.905 & \\
\hline SIP1 & & & & & 0.939 \\
\hline SIP2 & & & & & 0.904 \\
\hline SIP3 & & & & & 0.897 \\
\hline EC1 & & & & & \\
\hline
\end{tabular}

Values of composite reliability and item loadings have been checked for ensuring the reliability of constructs. The loadings were noted for the individual item reliability. The value of item loading must be higher or equal to 0.7, as per the thumb rule (Hair et al., 2016). It was acknowledged by Davcik and Sharma (2016) that the loadings of several items in the model could be less than 0.7 . Considering this, the current scales were changed to a new context. The ite ms having values of less than 0.7 were deleted until there was increase in the value of ACE of composite reliability (Hair et al., 2016). The composite reliability values were used for determining the reliability of constructs as recommended by Hair et al. (2016) in PLS-SEM method. Commonly, the researchers use the value of Cronbach's alpha for determining the internal consistency. It is not assumed by composite reliability that every indicator has the same reliability as assumed in the Cronbach's alpha. Moreover, it is greatly changes with the change in number of scale items (Hair et al., 2016). It has been shown in Table 2 that the value of composite reliability is greater than the standard value of 0.7 for every unobserved variable. The AVE value was used for the determination of convergent validity that must be higher than the value 0.50 (Hair et al., 2016). The value of AVE, which was lowers, is 0.51. Therefore, this fulfils the condition for all the constructs.

Table 2. Reliability.

\begin{tabular}{|l|l|l|l|l|}
\hline & Cronbach's Alpha & rho_A & CR & (AVE) \\
\hline EC & 0.902 & 0.903 & 0.939 & 0.837 \\
\hline PABCP & 0.926 & 0.928 & 0.944 & 0.773 \\
\hline RABCP & 0.967 & 0.968 & 0.971 & 0.771 \\
\hline SBR & 0.902 & 0.905 & 0.939 & 0.837 \\
\hline SIP & 0.900 & 0.901 & 0.938 & 0.834 \\
\hline
\end{tabular}

The internal consistency of every construct has been regarded as appropriate. Every construct must have more changes with its measures in contrast to the value of correlation with the other variables for ensuring discriminant validity. This is represented by the value of AVE square root in contrast to the correlation value (Hair et al., 2016; Tzempelikos \& Gounaris, 2017). The value of AVE square root must be equal or greater 
than 0.70 . It has been shown in Table 3 that this criterion has been fulfilled by all the constructs. This reflects that there is discriminant validity.

Table 3. Discriminant Validity.

\begin{tabular}{|l|l|l|l|l|l|}
\hline & EC & PABCP & RABCP & SBR & SIP \\
\hline EC & 0.915 & & & & \\
\hline PABCP & 0.883 & 0.879 & & & \\
\hline RABCP & 0.671 & 0.730 & 0.878 & & \\
\hline SBR & 0.811 & 0.807 & 0.697 & 0.905 & \\
\hline SIP & 0.639 & 0.722 & 0.810 & 0.669 & 0.913 \\
\hline
\end{tabular}

In the next phase, the structured model has been determined. It analyses the association between the variables. The structural model is tested in the next phase, in which the association between the unobserved variables is determined (Davcik \& Sharma, 2016; Tzempelikos \& Gounaris, 2017).

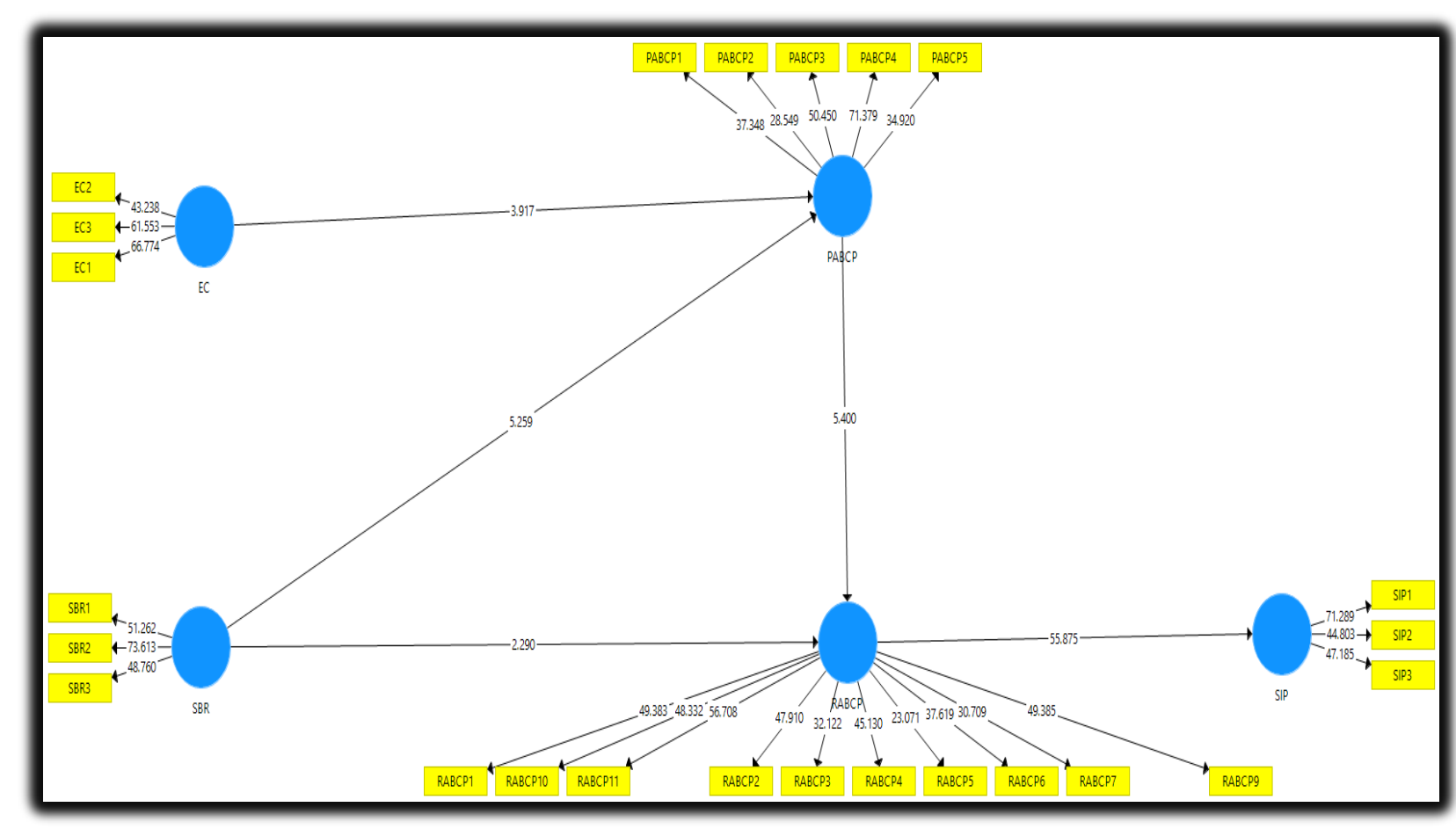

Figure 2. Structural Model.

The Structural model assessment includes five steps of estimates for i.e. collinearity issue, significance of association in the structural model, regression coefficient (R2), effect size (F2) and effect sizes (q2). A sample of 5000 bootstrap was used to calculate t-values (Hair et al., 2016). 
Table 4. Structural Results.

\begin{tabular}{|l|l|l|l|l|l|}
\hline & $(\mathbf{O})$ & $(\mathbf{M})$ & $(\mathbf{S T D E V})$ & $(\mathbf{O} / \mathrm{STDEV})$ & P Values \\
\hline EC $>>$ PABCP & 0.390 & 0.391 & 0.100 & 3.917 & $\mathbf{0 . 0 0 0}$ \\
\hline PABCP $>$ RABCP & 0.535 & 0.537 & 0.099 & 5.400 & $\mathbf{0 . 0 0 0}$ \\
\hline RABCP $>$ SIP & 0.910 & 0.911 & 0.016 & 55.875 & $\mathbf{0 . 0 0 0}$ \\
\hline SBR $>$ PABCP & 0.541 & 0.541 & 0.103 & 5.259 & $\mathbf{0 . 0 0 0}$ \\
\hline SBR $>$ RABCP & 0.217 & 0.217 & 0.095 & 2.290 & $\mathbf{0 . 0 1 1}$ \\
\hline
\end{tabular}

The explanatory power of explanatory variables for the dependent variable was determined by coefficient of determination (Hair et al., 2017). The range of R2 is $0-1$. The closer the value to 1 , the higher is the predictive power and vice versa.

Table 5. R-square

\begin{tabular}{|l|l|}
\hline & R Square \\
\hline PABCP & 0.830 \\
\hline RABCP & 0.542 \\
\hline SIP & 0.829 \\
\hline
\end{tabular}

The predictive relevance is found through effect size. The predictive relevance of the model is show by the value of Q2 (Hair et al., 2016). In case, the value comes out to be zero, the model has no predictive relevance.

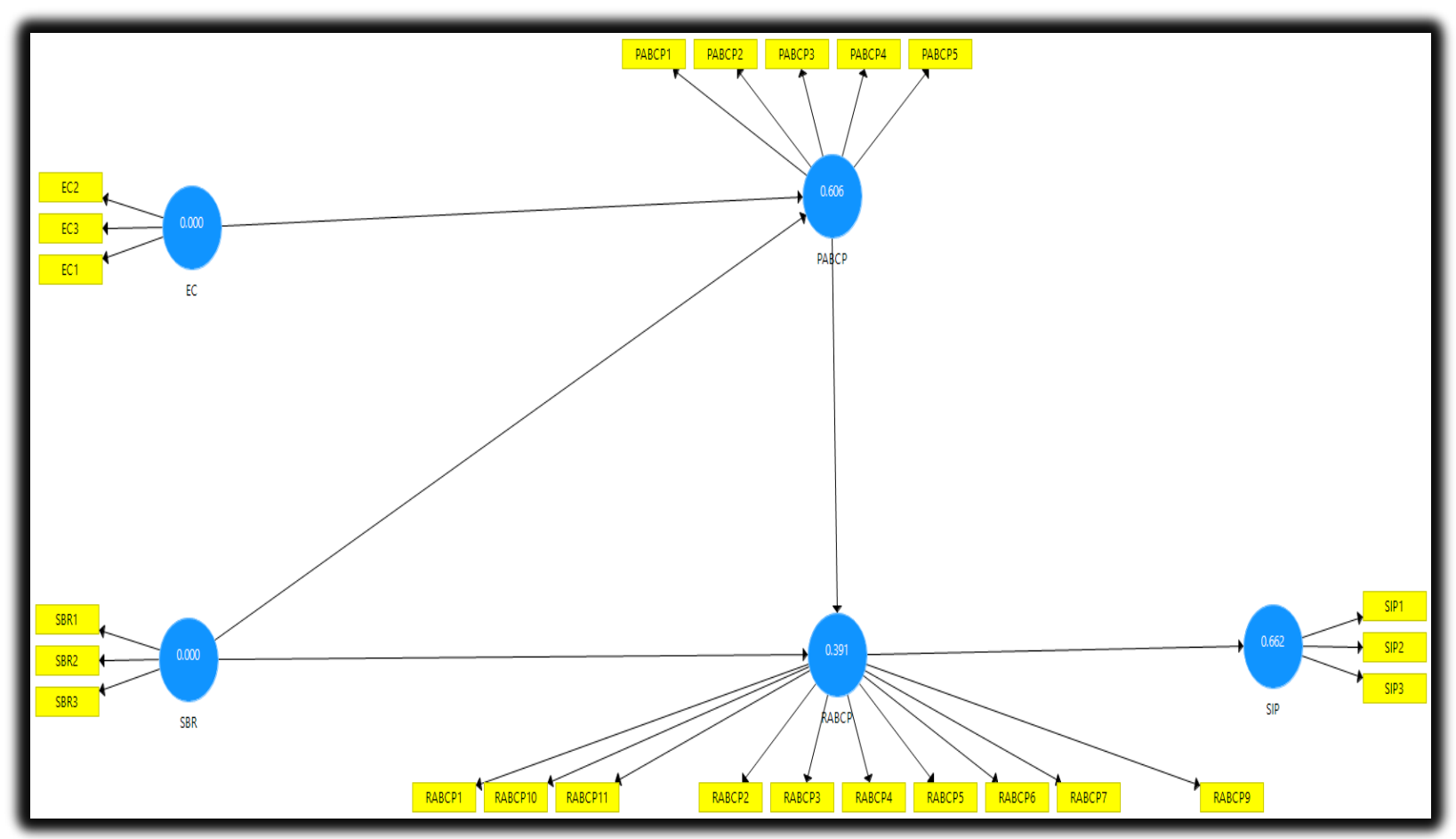

Figure 3. Q-square. 
Table 6. Q-square.

\begin{tabular}{|l|l|l|l|}
\hline & SSO & SSE & $\mathbf{Q}^{2}$ (=1-SSE/SSO) \\
\hline EC & 651.000 & 651.000 & \\
\hline PABCP & $1,085.000$ & 427.198 & 0.606 \\
\hline RABCP & $2,170.000$ & $1,321.914$ & 0.391 \\
\hline SBR & 651.000 & 651.000 & \\
\hline SIP & 651.000 & 220.155 & 0.662 \\
\hline
\end{tabular}

\section{DISCUSSION AND CONCLUSION}

The focus of SMEs in the manufacturing sector is increasing on the strategies of servitization (Visnjic et al., 2016). Irrespective of the concerned efforts, the service innovations cannot be achieved by most of the firms along with the expected benefits of servitization (Visnjic et al., 2016). A crucial way for achieving competitive advantage is offered by service innovations. It is crucial for the SMEs in manufacturing sector to deliver innovations in services in an effective way (Valtakoski et al., 2019). From the perspective of dynamic capability, ACAP being the potential antecedent of performance in service innovation of SMEs has been investigated empirically. Moreover, performance in service innovation can be derived through search breadth of SMEs by influencing employee collaboration and PACAP, and its influence on RACAP and PACAP. The performance of service innovation can be influenced positively through use of external knowledge via RACAP. Therefore, the performance of service innovation can be achieved by an SME in manufacturing sector when it possesses the ability to use the relevant knowledge gained from external sources. Moreover, it must have the capability of assimilating and utilizing the acquired knowledge. Performance in service innovation can be gained through employees' collaboration in the process of innovation through expanding all the ACAP's dimensions. The performance of service innovation is affected by the diversity of innovation partners through creating an influence on PACAP. Several contributions to the theory can be made by the results. The results help in understanding the way in which performance of service innovation can be achieved by the manufacturing SMEs. The research gives guidelines from the perspective of theory and management about the way to achieve competitive advantage. This has been done by reflecting that the capability of dynamic knowledge can be developed through collaboration internally and externally. This results in the achievement of competitive advantaged gained through service innovation. The study gives empirical support for the suggestion of Valtakoski et al. (2019) that performance of service innovation can be derived by ACAP. It has been suggested by some researchers that there is need for dynamic capabilities in the initial phase of servitization. However, dynamic capabilities to be the success factors for the performance of servitization performance have not been observed. This research gap has been dealt in this study and ACAP has been regarded as the dynamic capability for enhancing the performance of service innovation. In this regard, contributions have been made to the literature by discussing about the need for radical change for achieving servitization in the organization. Organizations need to consider their operations. The factors determining the achievement of success of service innovation are different from those resulting in the performance of product innovation. For this reason, several organizations have failed to servitize in a successful way. This has influenced some researchers to recommend that a new approach be required by servitization (Benedettini et al., 2015). It was claimed by Valtakoski et al. (2019) that there is need for adapting capabilities and practices of innovation by the manufacturing firms aiming at servitization for differentiating the products and services. It has been shown by the findings that both innovation types are derived through the similar mechanisms of knowledge. The positive influence created on product innovation by ACAP has been confirmed by previous research (Asimakopoulos et al., 2019). It has been shown that performance of service innovation is derived by ACAP. The difference exists in the type of knowledge gained from external sources, which has been assimilated, used, and transformed. It is difficult to manage the relevant knowledge 
because of intangible nature of services. There are some limitations of our findings as well. The ability to determine the associations between variables is limited through the cross-sectional nature of data. The sequencing of the influences found was not testing. The level of employee involvement in the process of service innovation is strengthened through the successful service innovation. Conclusive evidence was not provided by the longitudinal data for temporal sequencing of the influences. Further, the results of this research cannot be applied to any other sector and it has regional applicability. It cannot be generalized. The assessment of the model has been done based on the sample of companies manufacturing sports products in Thailand. The issue of selection bias was not identified in the study. However, the representativeness of the sample used is limited by the servitizing manufacturing SMEs. The difference between the types of innovations was not found by the data used in this study. The drivers influencing performance of service innovation are not identical among various types of innovation service. This needs to be investigated in future studies. The typology can be used by the researchers to analyse the effects created on different service innovations by ACAP. Moreover, it can be analysed whether the development of ACAP is different in the SMEs of manufacturing sector, which aim to servitize. There is need for change of mindset across the organization in order to achieve performance of service innovation (Benedettini et al., 2015). It has been suggested by this research that employee collaboration should be ensured by SMEs in the process of service innovation. However, future studies can analyse the way in which the adoption of this mind set can be established by the manufacturing SMEs. Organizations should invest in motivating employees and improving their capabilities through training. It would be interesting to analyse the way in which employee collaboration can be stimulated by the managers such as by innovation support that can result in successful servitization and performance of service innovation.

\section{REFERENCES}

Arndt, F., \& Bach, N. (2015). Evolutionary and Ecological conceptualization of dynamic capabilities: Identifying elements of the Teece and Eisenhardt schools. Journal of Management \& Organization, 21(5), 701-704. https://doi.org/10.1017/jmo.2015.22

Asimakopoulos, G., Revilla, A. J., \& Slavova, K. (2019). External Knowledge Sourcing and Firm Innovation Efficiency. British Journal of Management. https://doi.org/10.1111/1467-8551.12367

Benedettini, O., Neely, A., \& Swink, M. (2015). Why do servitized firms fail? A risk-based explanation. International Journal of Operations \& Production Management, 35(6), 946-979. https://doi.org/10.1108/ijopm-02-2014-0052

Broersma, R., Van Gils, A., \& De Grip, A. (2016). Ambidexterity in SMEs: Role of Absorptive Capacity and CEO's strategic engagement. Paper presented at the Academy of Management Proceedings. https://doi.org/10.5465/ambpp.2016.201

Brunswicker, S., \& Vanhaverbeke, W. (2015). Open innovation in small and medium-sized enterprises (SMEs): External knowledge sourcing strategies and internal organizational facilitators. Journal of Small Business Management, 53(4), 1241-1263. https://doi.org/10.1111/jsbm.12120

Dada, O., \& Fogg, H. (2016). Organizational learning, entrepreneurial orientation, and the role of university engagement in SMEs. International Small Business Journal, 34(1), 86-104. https://doi.org/10.1177/0266242614542852

Davcik, N. S., \& Sharma, P. (2016). Marketing resources, performance, and competitive advantage: A review and future research directions. Journal of Business Research, 69(12), 5547-5552. https://doi.org/10.1016/j.jbusres.2016.04.169

Fainshmidt, S., \& Frazier, M. L. (2017). What facilitates dynamic capabilities? The role of organizational climate for trust. Long Range Planning, 50(5), 550-566. https://doi.org/10.1016/j.Irp.2016.05.005 
Fernández-Mesa, A., \& Alegre, J. (2015). Entrepreneurial orientation and export intensity: Examining the interplay of organizational learning and innovation. International Business Review, 24(1), 148-156. https://doi.org/10.1016/.i.busrev.2014.07.004

Gopal, P., \& Thakkar, J. (2016). Sustainable supply chain practices: an empirical investigation on Indian automobile industry. Production Planning \& Control, 27(1), 49-64. https://doi.org/10.1080/09537287.2015.1060368

Hair, Hult, G. T. M., Ringle, C., \& Sarstedt, M. (2016). A primer on partial least squares structural equation modeling (PLS-SEM): Sage publications. https://doi.org/10.3926/oss.37

Hair, Hult, G. T. M., Ringle, C. M., \& Thiele, K. O. (2017). Mirror, mirror on the wall: a comparative evaluation of composite-based structural equation modeling methods. Journal of the Academy of Marketing Science, 45(5), 616-632. https://doi.org/10.1007/s11747-017-0517-x

Harris, E. E., \& Neely, D. G. (2016). Multiple information signals in the market for charitable donations. Contemporary Accounting Research, 33(3), 989-1012. https://doi.org/10.1111/1911-3846.12175

Helfat, C. E., \& Peteraf, M. A. (2015). Managerial cognitive capabilities and the microfoundations of dynamic capabilities. Strategic Management Journal, 36(6), 831-850. https://doi.org/10.1002/smi.2247

Hewitt-Dundas, N., \& Roper, S. (2018). Exploring market failures in open innovation. International Small Business Journal, 36(1), 23-40. https://doi.org/10.1177/0266242617696347

Hotho, J. J., Lyles, M. A., \& Easterby-Smith, M. (2015). The mutual impact of global strategy and organizational learning: Current themes and future directions. Global Strategy Journal, 5(2), 85-112. https://doi.org/10.1002/gsi.1097

Hsiao, Y.-C., \& Wu, M.-H. (2019). How organizational structure and strategic alignment influence new product success. Management Decision. https://doi.org/10.1108/md-06-2017-0628

Jermsittiparsert, K. \& Srisawat, S. (2019). Complexities in a Flexible Supply Chain and the Role of Knowledge Transfer. Humanities and Social Sciences Reviews, 7(2), 531-538. https://doi.org/10.18510/hssr.2019.7263

Jermsittiparsert, K., Sutduean, J., \& Sriyakul, T. (2019). Effect of Service Innovation and Market Intelligence on Supply Chain Performance in Indonesian Fishing Industry. Industrial Engineering \& Management Systems, 18(3), 408-417. https://doi.org/10.7232/iems.2019.18.3.407

Kleinbaum, A. M., \& Stuart, T. E. (2014). Inside the black box of the corporate staff: Social networks and the implementation of corporate strategy. Strategic Management Journal, 35(1), 24-47. https://doi.org/10.1002/smj.2090

Kohtamäki, M., \& Partanen, J. (2016). Co-creating value from knowledge-intensive business services in manufacturing firms: The moderating role of relationship learning in supplier-customer interactions. Journal of Business Research, 69(7), 2498-2506. https://doi.org/10.1016/i.jbusres.2016.02.019

Karle Pravin P, Dhawale Shashikant C. "Manilkara zapota (L.) Royen Fruit Peel: A Phytochemical and Pharmacological Review." Systematic Reviews in Pharmacy 10.1 (2019), 11-14. https://doi.org/10.5530/srp.2019.1.2

Lucangioli.S. "Acute Renal Failure: An Article Critique." International Journal of Pharmacy Research \& Technology 8.2 (2018), 51-52. https://doi.org/10.31838/ijprt/08.02.07

Lee, J.-C., \& Chen, C.-Y. (2019). The Moderator of Innovation Culture and the Mediator of Realized Absorptive Capacity in Enhancing Organizations' Absorptive Capacity for SPI Success. Journal of Global Information Management (JGIM), 27(4), 70-90. https://doi.org/10.4018/igim.2019100104

Love, J. H., \& Roper, S. (2015). SME innovation, exporting and growth: A review of existing evidence. International Small Business Journal, 33(1), 28-48. https://doi.org/10.1177/0266242614550190 
Luño, A., Saparito, P., \& Gopalakrishnan, S. (2016). Small and Medium-Sized Enterprise's Entrepreneurial versus Market Orientation and the Creation of Tacit Knowledge. Journal of Small Business Management, 54(1), 262-278. https://doi.org/10.1111/jsbm.12144

Martín-Peña, M.-L., Sánchez-López, J.-M., \& Díaz-Garrido, E. (2019). Servitization and digitalization in manufacturing: the influence on firm performance. Journal of Business \& Industrial Marketing. https://doi.org/10.1108/ibim-12-2018-0400

Meik, J., \& Brock, C. (2016). A conceptual contribution to research on stimulating service innovation-The interrelation of service innovation and customer complaint management Thriving in a New World Economy (pp. 385-385): Springer. https://doi.org/10.1007/978-3-319-24148-7_115

Melton, H. L., \& Hartline, M. D. (2013). Employee collaboration, learning orientation, and new service development performance. Journal of Service Research, 16(1), 67-81. https://doi.org/10.1177/1094670512462139

Mennens, K., Odekerken, G., \& Letterie, W. (2018). Exploring antecedents of service innovation performance in manufacturing SMEs. International Small Business Journal, 36(5), 500-520. https://doi.org/10.1177/0266242617749687

Morgan, T., Anokhin, S., \& Wincent, J. (2018). When the fog dissipates: The choice between value creation and value appropriation in a partner as a function of information asymmetry. Journal of Business Research, 88, 498-504. https://doi.org/10.1016/i.jbusres.2017.11.032

Noor, N. A. M., \& Aljanabi, A. Q. R. A. (2016). Moderating role of absorptive capacity between entrepreneurial orientation and technological innovation capabilities. International Review of Management and Marketing, 6(4), 704-710. https://doi.org/10.5539/ass.v11n5p219

Ringle, C. M., Wende, S., \& Becker, J.-M. (2015). SmartPLS 3. Bönningstedt: SmartPLS. Retrieved July, $15,2016$.

Roberts, N. (2015). Absorptive capacity, organizational antecedents, and environmental dynamism. Journal of Business Research, 68(11), 2426-2433. https://doi.org/10.1016/j.jbusres.2015.02.019

Rodríguez-Serrano, M. Á., \& Martín-Armario, E. (2019). Born-Global SMEs, Performance, and Dynamic Absorptive Capacity: Evidence from Spanish Firms. Journal of Small Business Management, 57(2), 298-326. https://doi.org/10.1111/jsbm.12319

Sarstedt, M., Hair, J. F., Ringle, C. M., Thiele, K. O., \& Gudergan, S. P. (2016). Estimation issues with PLS and CBSEM: Where the bias lies! Journal of Business Research, 69(10), 3998-4010. https://doi.org/10.1016/j.jbusres.2016.06.007

Semrau, T., Ambos, T., \& Kraus, S. (2016). Entrepreneurial orientation and SME performance across societal cultures: An international study. Journal of Business Research, 69(5), 1928-1932. https://doi.org/10.1016/i.jbusres.2015.10.082

Suda, H. (2018). The Influence of Organizational Environment on Corporate Messages of Japanese Companies. Paper presented at the 21 ST International Public Relations Research Conference.

Sutduean, J., Harakan, A., \& Jermsittiparsert, K. (2019). Exploring the Relationship between Supply Chain Integration, Product Innovation, Supply Chain Performance and Firm Performance: Does Supply Chain Information Strategy Matter?. International Journal of Innovation, Creativity and Change, 5(2), 175-192. https://doi.org/10.18510/hssr.2019.73102

Tzempelikos, N., \& Gounaris, S. (2017). A conceptual and empirical examination of key account management orientation and its implications-the role of trust The Customer is NOT Always Right? Marketing Orientationsin a Dynamic Business World (pp. 673-681): Springer. https://doi.org/10.1007/978-3-319-50008-9_185

Valtakoski, A., Reynoso, J., \& Maranto, D., Edvardsson, Bo. (2019). Cross-country differences in new service development: The moderating effects of national culture. Journal of Service Management, 30(2), 186-208. https://doi.org/10.1108/josm-05-2018-0134 
Visnjic, I., Wiengarten, F., \& Neely, A. (2016). Only the brave: Product innovation, service business model innovation, and their impact on performance. Journal of Product Innovation Management, 33(1), 3652. https://doi.org/10.1111/jpim.12254

Vrontis, D., Thrassou, A., \& Santoro, G., Papa, Armando. (2017). Ambidexterity, external knowledge and performance in knowledge-intensive firms. The Journal of Technology Transfer, 42(2), 374-388. https://doi.org/10.1007/s10961-016-9502-7

Wilden, R., Devinney, T. M., \& Dowling, G. R. (2016). The architecture of dynamic capability research identifying the building blocks of a configurational approach. Academy of Management Annals, 10(1), 997-1076. https://doi.org/10.5465/19416520.2016.1161966

Wu, I.-L., \& Hu, Y.-P. (2018). Open innovation based knowledge management implementation: a mediating role of knowledge management design. Journal of Knowledge Management, 22(8), 17361756. https://doi.org/10.1108/jkm-06-2016-0238 